Acta vet. scand. $1976,17,328-342$.

From the Section of Occupational Toxicology, National Board of Occupational Safety and Health, Stockholm, and the National Veterinary Institute, Stockholm, Sweden.

\title{
THE PATHOLOGY OF VINYL CHLORIDE EXPOSED MICE*
}

\author{
By
}

B. Holmberg, T. Kronevi and M. Winell

HOLMBERG, B., T. KRONEVI and M. WINELL: The pathology of vinyl chloride exposed mice. Acta vet. scand. 1976, 17, 328-342. Outbred albino laboratory mice were exposed to 50 p.p.m. and 500 p.p.m. vinyl chlonide by inhalation $6 \mathrm{hrs}$./day, 5 days/week during 52 and 26 weeks, respectively. Pathologic examination showed the presence of histologically benign alveologenic lung adenomas, haemangiosarcomas in fat tissue as well as a few benign and malignant tumours at various sites. Only one liver haemangiosarcoma was noted. All animals exposed to 500 p.p.m. developed tumours; $71 \%$ of the animals given 50 p.p.m. were tumour bearing. The frequency of all tumours, number of tumour foci and size of foci in both groups suggest a dose-dependent carcinogenic effect of vinyl chloride. Haemocoelia due to blood vessel rupture was a common cause of death. Telangiectasis of the liver was also observed in a few animals. The role of fat tissue as well as blood vessel involvement in the pathology of vinyl chloride is discussed.

vinyl chloride; haemangiosarcoma; mouse; carcinogenicity; fat $t$ issue; blood vessel.

Vinyl chloride (VC, monochloroethylene) has been demonstrated to possess mutagenic (Ducatman et al. 1975, Rannug et al. 1975, Loprieno et al. 1976, Funes-Cravioto et al. 1975, Bartsch \& Montesano 1975) and carcinogenic activities (Viola et al. 1971, Maltoni 1975) in experimental test systems and has also been established as an occupational hazard (Lloyd 1975, Tabershau) \& Gaffey 1974) to workers in the VC production and polymerization industries in several countries.

In connection with a study reported elsewhere (Winell et al. 1976) on plasma enzyme variations associated with liver injury Fund.

* This work was supported by the Swedish Work Environment 
and tumour occurrence in mice after chronic VC exposure some pathologic observations were reported. Detailed results of the pathologic examination are reported here.

\section{MATERIALS AND METHODS}

Outbred albino NMRI mice were taken for experiment at 12 weeks of age. Twenty-four animals, 12 males and 12 females, were exposed in each group to 50 or 500 p.p.m. $\pm 10 \% \mathrm{VC}, 6 \mathrm{hrs}$./ day, five days/week.

One control series was run parallel to the 50 p.p.m. series, which was exposed for 52 weeks. Another control series was run parallel to the 500 p.p.m. series, which was exposed for 26 weeks. Those two series were started two months after the 50 p.p.m. and corresponding control series. In all series, four animals of each sex were sacrificed and subjected to pathological examination 26 weeks after start of exposure. Furthermore, four control animals were sacrificed one year after the start of experiment. The rest of the animals were subjected to pathological examination when moribund or spontaneously dead. All animals in the 50, 500 p.p.m. and one of the control series were kept in dark cylindric metal inhalation chambers (air volume 20 1) in which a constant flow of air was introduced. Air content of VC was analysed regularly by gas chromatography for control of the VC concentration. One control series, which was started at the same time as the 500 p.p.m. series, was kept in laboratory air outside the inhalation chamber. As no significant difference was observed between the two control series their data were treated together. Food and water were withdrawn during the daily exposure for all groups.

Total body weight was registered every two weeks. Spleen and liver of all animals were weighed. All mice were necropsied. Material for histological examination was fixed in $10 \%$ neutral formalin. Eye and liver were fixed also in Bouin fluid.

Spleen, lung, liver, kidney and brain as well as those organs and tissues where tumours were visible were histologically examined in all mice. In several mice of each group the following organs were also histologically examined: skeletal muscle, myocardium, oesophagus, trachea, thyroid, brown fat, parotis, spinal cord, eye, lacrimal gland, eyelids, stomach, pancreas, small and large intestine, mesenteric lymph nodes, ovary, uterus, testicle, seminal vesicle, urinary bladder, bone marrow, and metatarsus. 

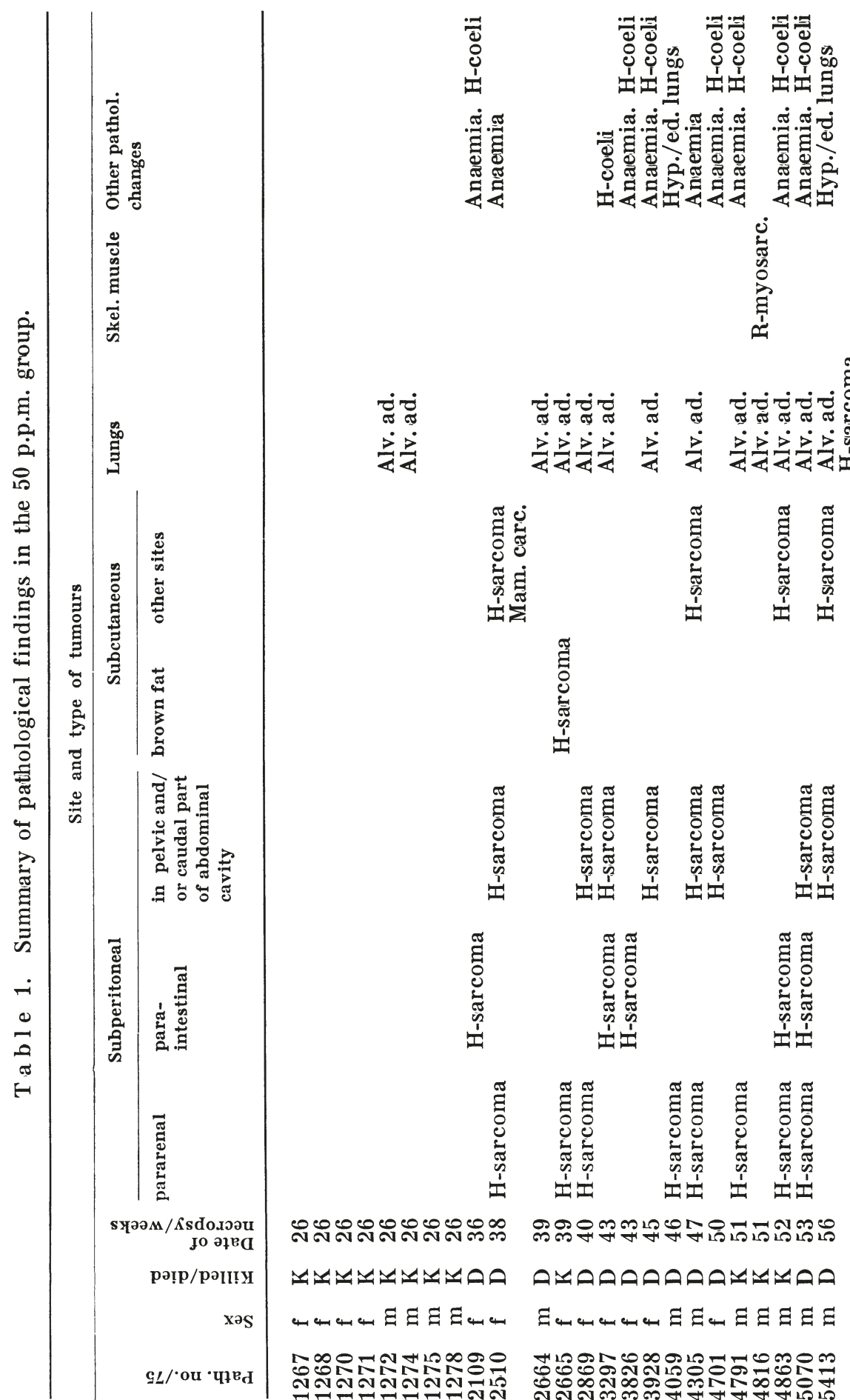

安完
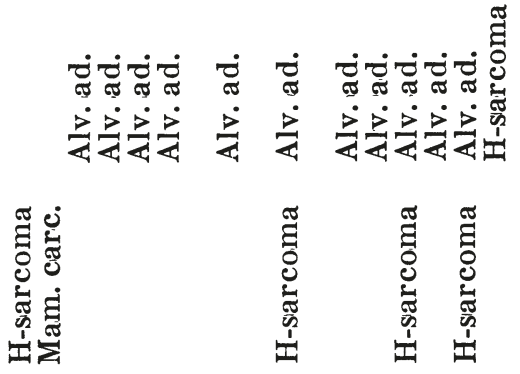

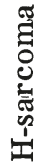
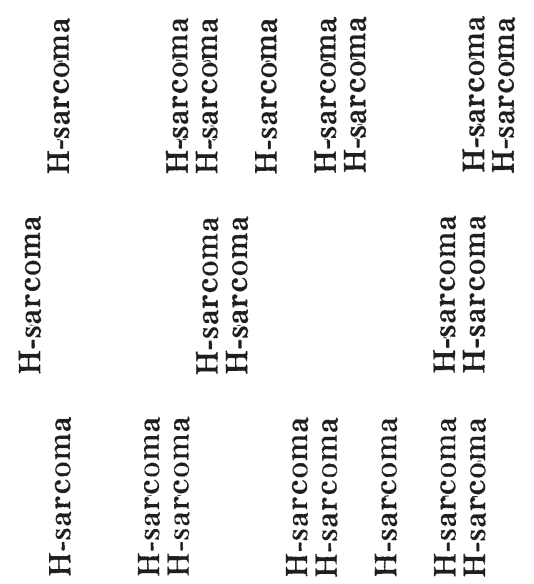

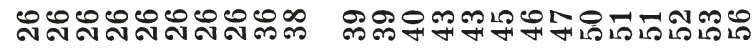
ะ

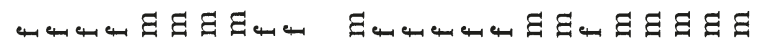

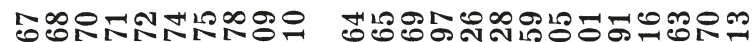
งัง ง บง

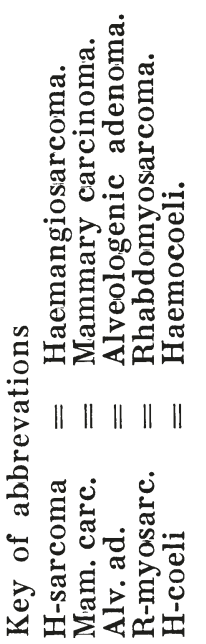




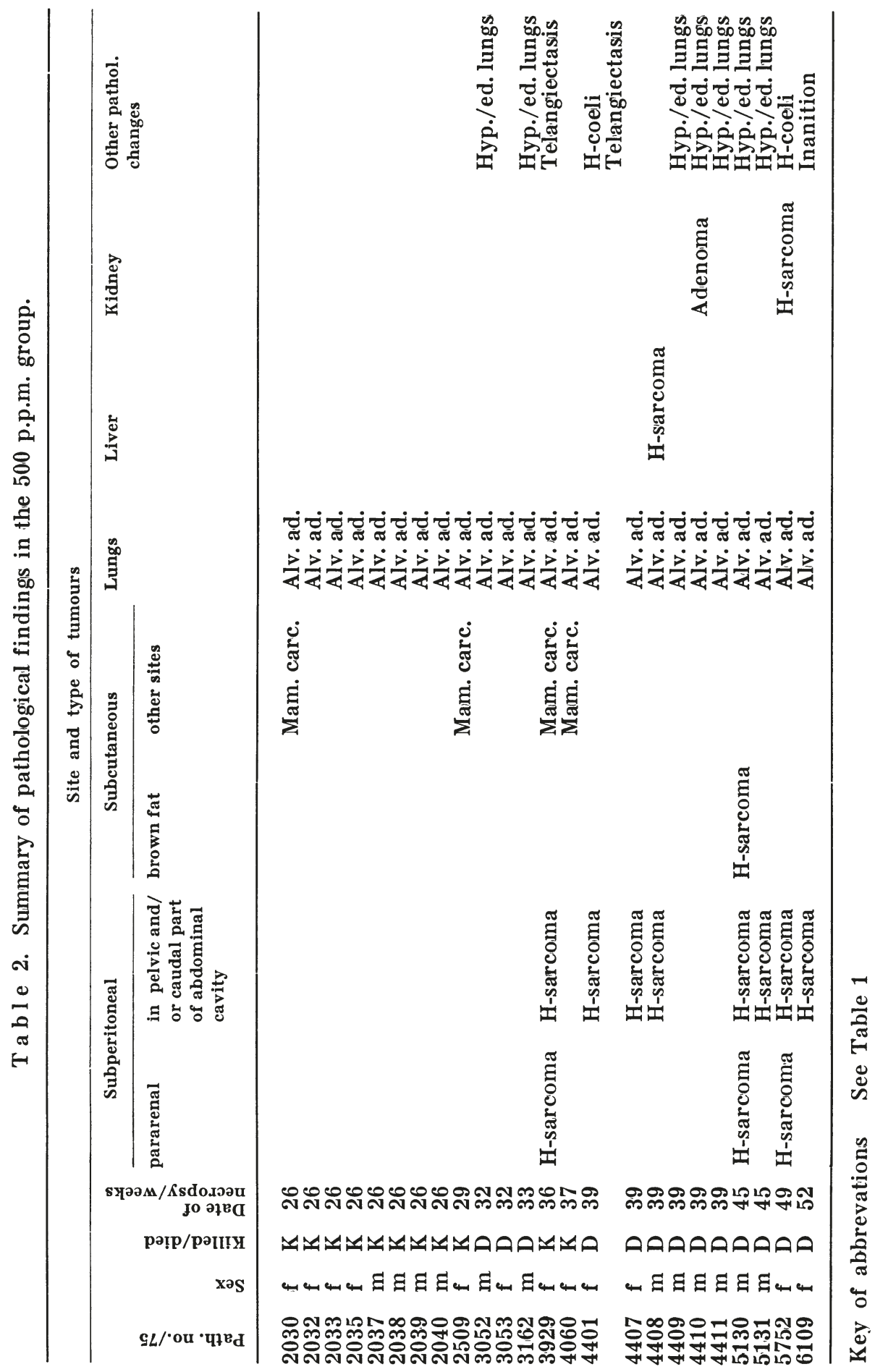



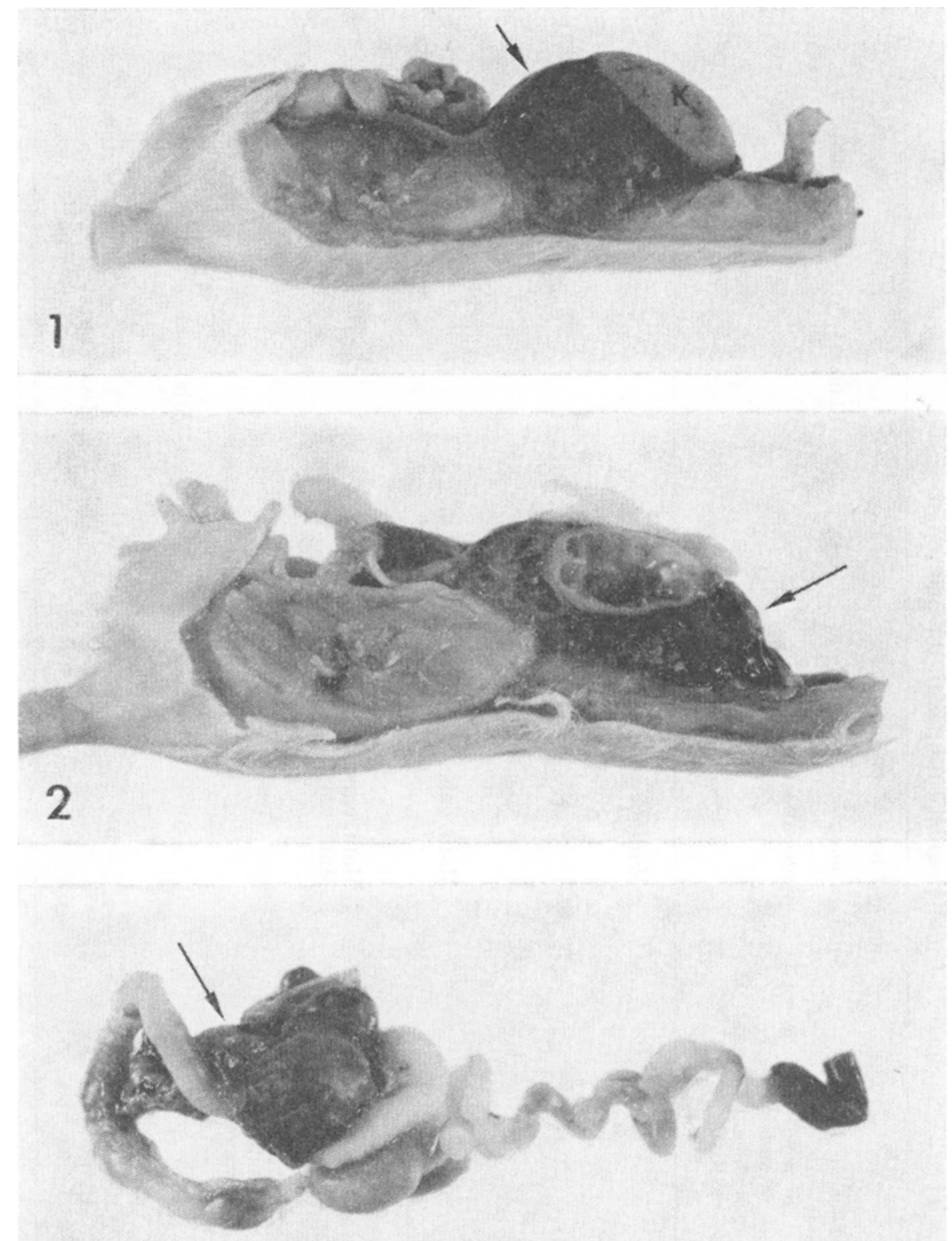

3

Figure 1. Pararenal haemangiosarcoma (arrow). 50 p.p.m. series. Haemangiosarcoma is adherent to the kidney $(K)$, but does not infiltrate normal kidney tissue. The tumour does, however, infiltrate the sublumbar muscle.

Fig u r e 2. Pararenal haemangiosarcoma (arrow). 50 p.p.m. series. Haemangiosarcoma is adherent to the kidney, but does not infiltrate normal kidney tissue. Note renal cysts.

Figure 3. Paraintestinal haemangiosarcoma (arrow). 50 p.p.m. series. 

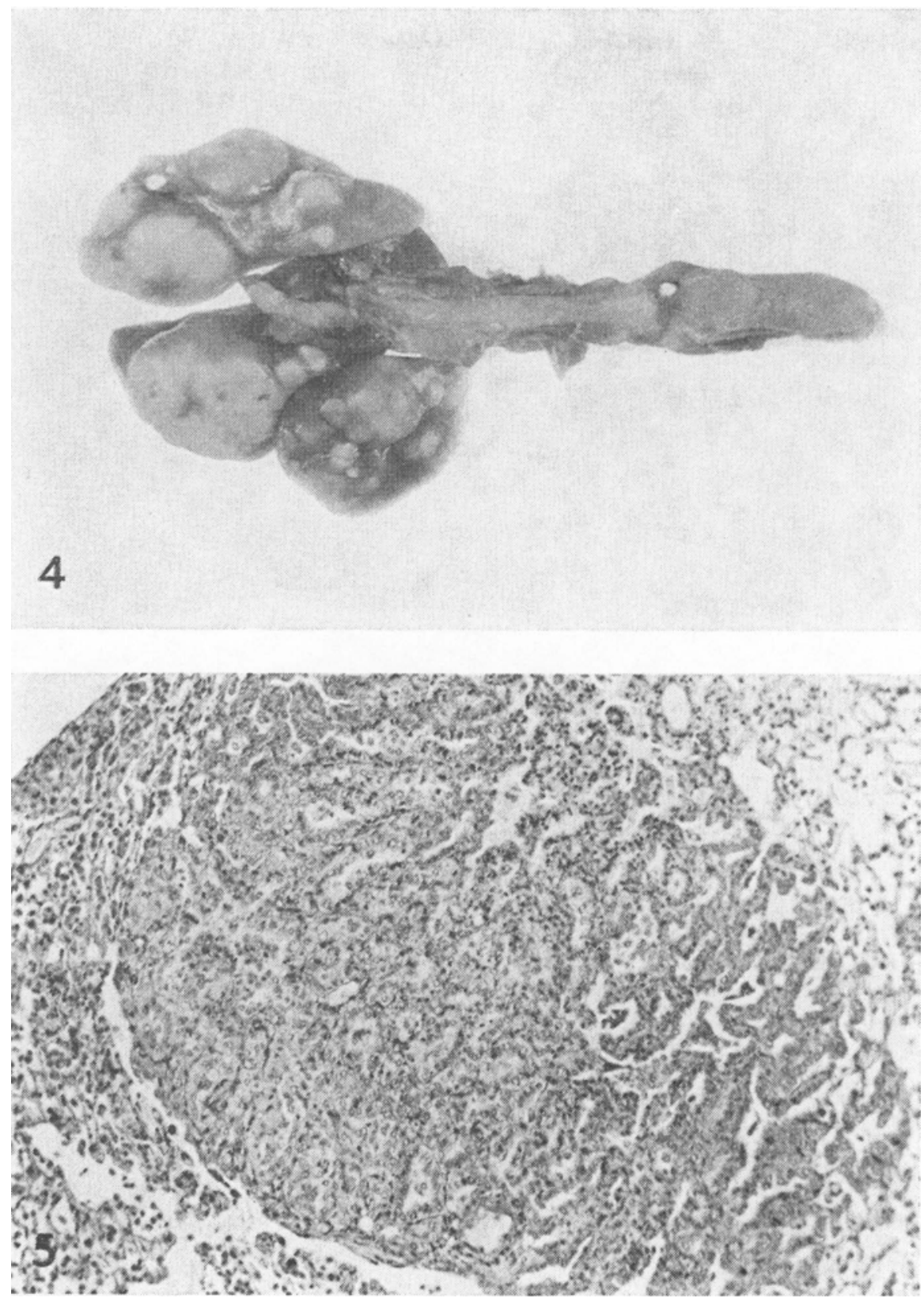

Figure 4. Lungs. Multiple alveologenic adenomas. 500 p.p.m. series.

F i g u r e 5. Lungs. Alveologenic adenoma. 500 p.p.m. series. $H$ and E. $\times 32$. 

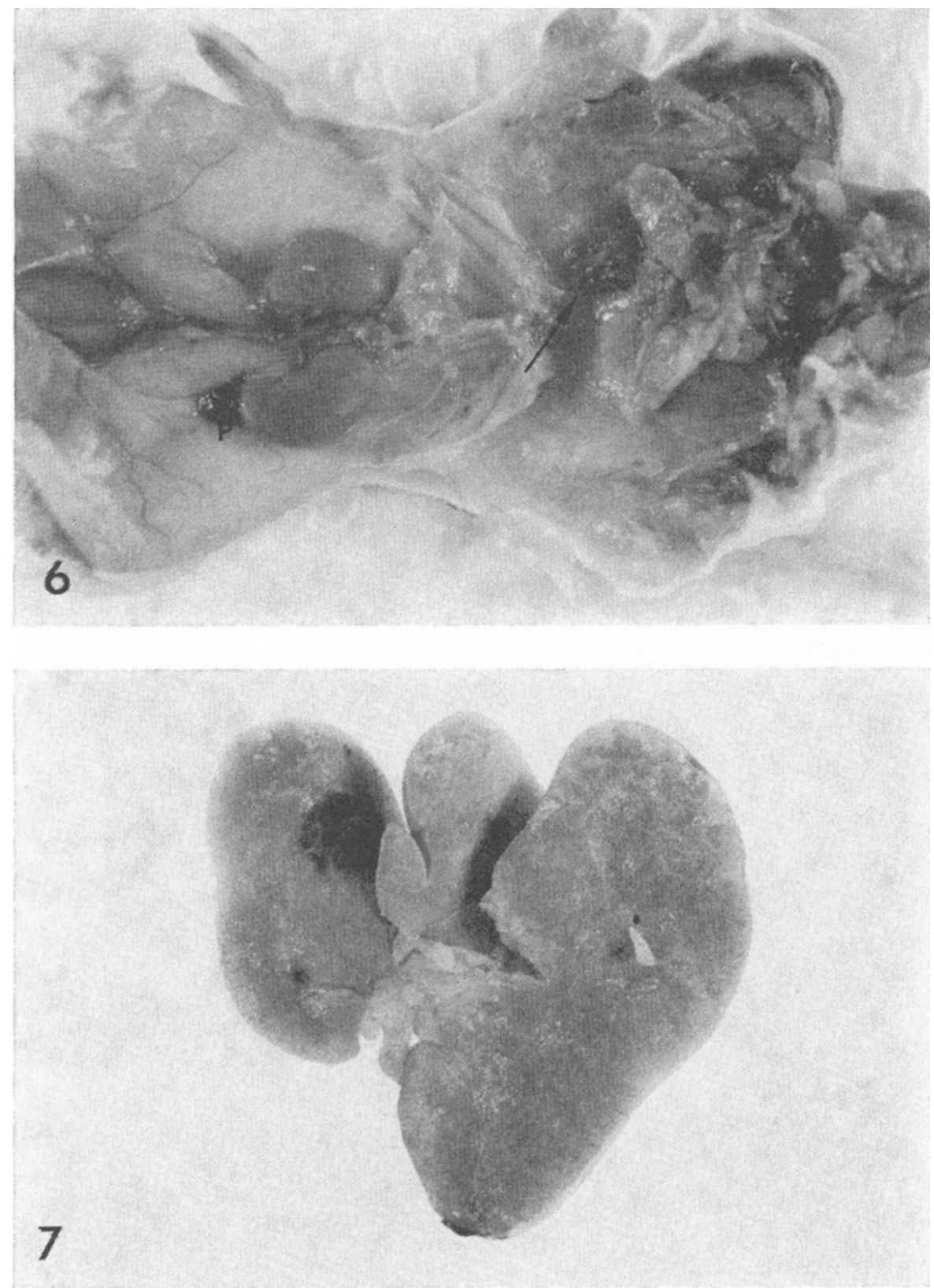

F ig u r e 6. Haemangiosarcoma in brown fat tissue. (Arrow). 500 p.p.m. series. Note also pararenal haemangiosarcoma. (P). F i g u r e 7. Liver. Telangiectasis. 500 p.p.m. series. 


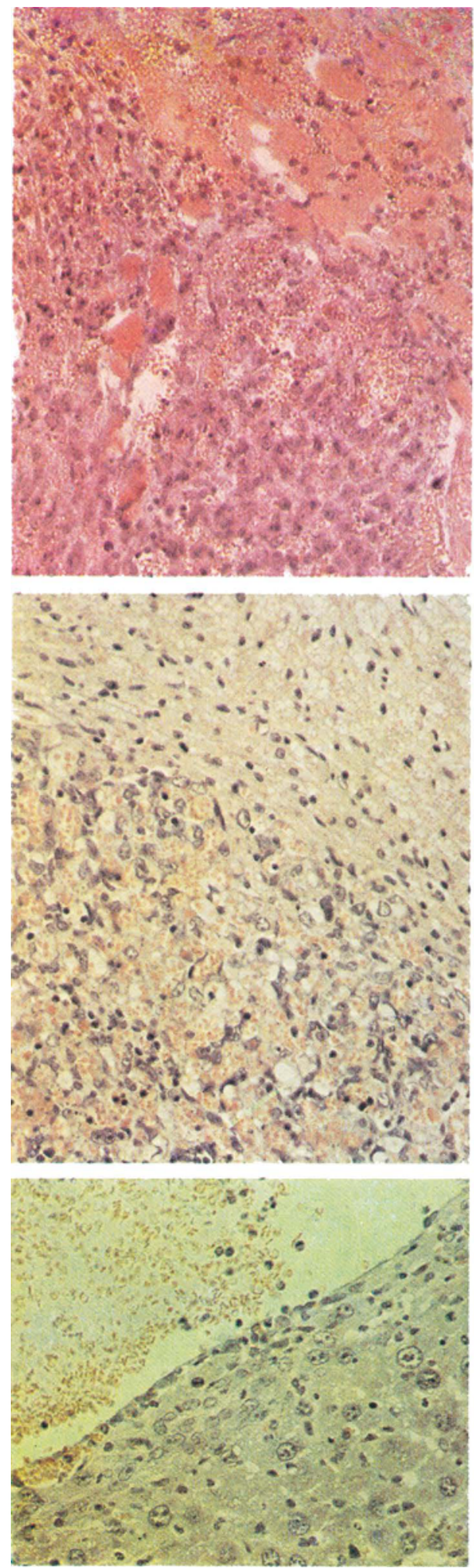
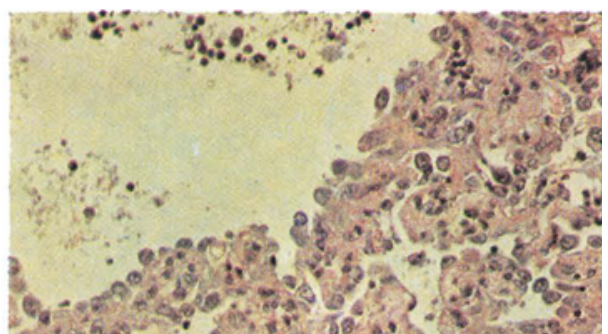

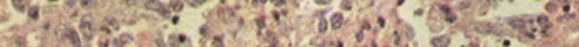

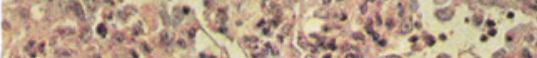

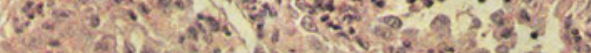

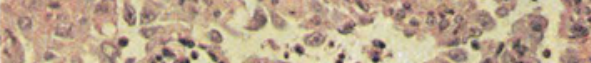

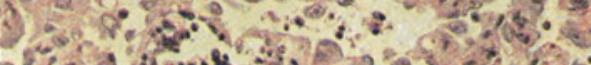
s.

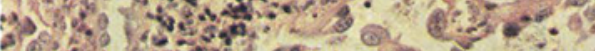

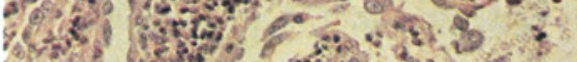

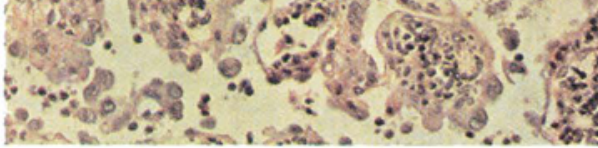
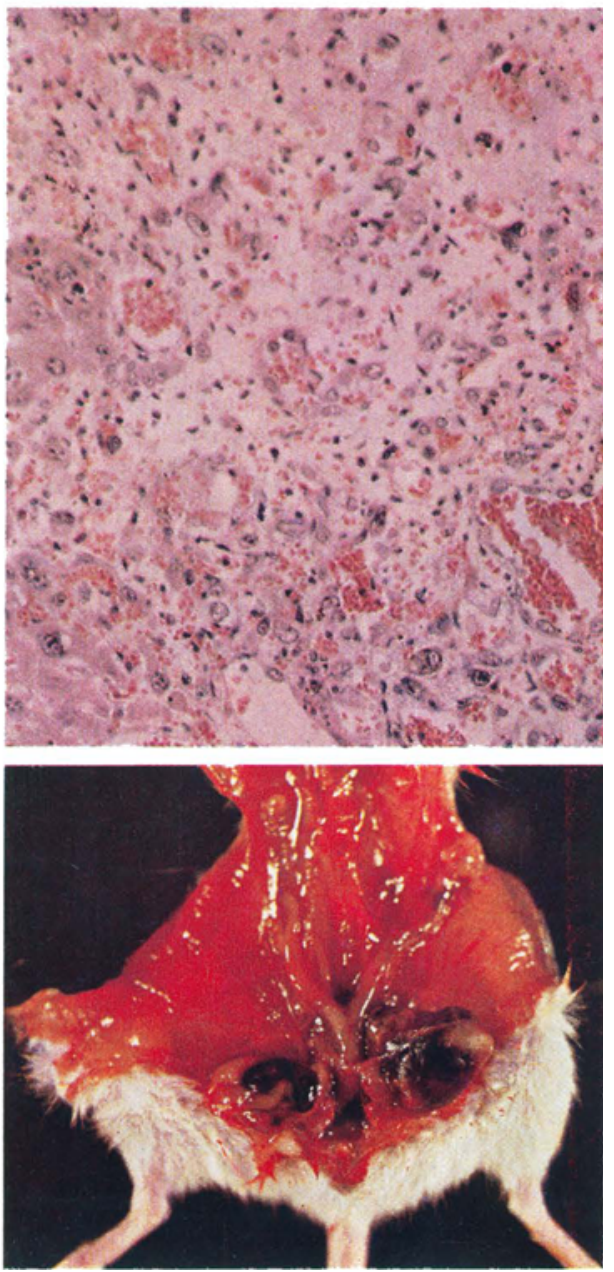
Frozen sections of skeletal muscle, myocardium, liver and kidney as well as some tumour and lung tissue sections were stained with scarlet red.

All embedded sections were stained with haematoxylin and eosin (HE). The tumours and some other organs were also stained with van Gieson, PAS and Pearl's method for ferric iron.

\section{RESULTS}

The total body weight of exposed animals did not increase at the same rate as non-exposed animals. Thus, from 24 weeks after start of exposure the total body weight curves of both exposed groups reached a plateau. After 40 weeks a decrease in body weight could generally be observed in exposed animals. Body fat was also reduced in VC-treated mice at the later half of the experiment. Spleen and liver weights fell within the normal range throughout the observation time. No significant difference in tissue or total body weights between the two exposed animal series could be observed.

Two control animals died two months after start of experiment, one during anaesthesia and the other by unknown cause.

In control series three animals out of a total of 48 animals were observed with tumours. One animal had a mammary adenocarcinoma on the left side of the chest with pulmonary metastasis occurring 38 weeks after exposure. The second animal was observed with a disgerminoma of the ovary at 46 weeks and the third animal died at 65 weeks with a reticulum cell sarcoma of the spleen and mesenteric lymph nodes. No other significant pathologic changes were observed in control animals.

The main features of the histopathologic data in VC-exposed

Figure 8. Haemangiosarcoma from pelvic/caudal part of the abdominal cavity. 50 p.p.m. series. Note that tumour tissue is embedded in fat tissue. Scarlet red.

Figure 9. Haemangiosarcoma from pelvic/caudal part of abdominal cavity. 500 p.p.m. series. $H$ and $E$.

F i g u r e 10 . Haemangiosarcoma in the brown fat tissue. 500 p.p.m. series. $\mathrm{H}$ and $\mathrm{E}$.

F i g u r 11. Liver haemangiosarcoma. 500 p.p.m. series. H and E.

F i g u r e 12 . Liver. Telangiectasis. 500 p.p.m. series. $H$ and E.

F i g u r e 13 . Haemangiosarcoma embedded in fat tissue is seen on each side of the uterus. 50 p.p.m. series. 
animals are displayed in Tables 1 and 2 and summarized as follows.

A total of 18 animals out of 24 in those series exposed to 50 p.p.m. for 52 weeks were bearing a tumour. Two animals out of eight sacrificed at 26 weeks after start of exposure had lung adenomas (Table 1). All animals necropsied thereafter were bearing tumours. Alveologenic adenomas were found in 13 animals out of 24. The lung tumours were often single or multiple with generally a few foci with approximate diameters up to 0.2 $\mathrm{cm}$. One lung adenoma bearing animal also had a secondary haemangiosarcoma in the lung originating from a primary subcutaneous tumour of the throat region $(5413 / 75)$. Subperitoneal haemangiosarcomas were found in 14 animals distributed pararenally (Figs. 1 and 2) and paraintestinally (Fig. 3), and in the pelvic/caudal part (Figs. 8 and 13) of the abdomen. In cases of pararenal haemangiosarcomas, tumour tissue was microscopically well separated from normal kidney tissue.

Subcutaneous tumours occurred in five animals, all bearing haemangiosarcomas in brown fat or other sites. One of those also had a mammary adenocarcinoma (2510/75). Rhabdomyosarcoma of the left thigh was found in one case (4816/75). Among other pathologic changes rupture of haemangiosarcomas causing haemocoelia occurred in eight animals.

In animals exposed to 500 p.p.m. dyspnoea was frequently noticed long before any other symptoms. The exposure to 500 p.p.m. was terminated at 26 weeks due to bad general condition of the majority of animals in these series.

Inhalation of 500 p.p.m. for 26 weeks induced alveologenic adenomas in all mice (Table 2). The lung tumours in these series were multiple and were present in all lung lobes with 10 or more foci (Figs. 4 and 5). The approximate diameters of foci were up to $0.9 \mathrm{~cm}$. Lung tumours were present also in all those mice which were killed at 26 weeks after start of exposure.

Eight mice had subperitoneal haemangiosarcomas in the pelvic/caudal part of the abdomen (Fig. 9). Three of those also had pararenal haemangiosarcomas. Mammary adenocarcinomas appeared in four animals. Only one animal had haemangiosarcoma of the liver (4408/75; Fig. 11) and one animal bore an adenoma of the kidney (4410/75). A haemangiosarcoma in brown fat (Figs. 6 and 10) was seen in one case (5130/75).

Among other pathological changes than neoplasia, telangi- 
ectasis (Figs. 7 and 12) of the liver and rupture of haemangiosarcomas causing haemocoelia were observed in a few animals exposed to 500 p.p.m.

All primary subcutaneous and subperitoneal haemangiosarcomas were located in fat tissue both in the 50 p.p.m. and 500 p.p.m. series. No liver fibrosis was observed in any animal, nor was any pathological change observed in the spleen of exposed animals.

At 26 weeks, eight animals were randomly chosen and sacrificed. The mean survival time of the remaining animals was 46 weeks for the 50 p.p.m. series and 35 weeks for the 500 p.p.m. series. In the 50 p.p.m. series the mean survival times were 42 weeks for females and 49 weeks for males. In the 500 p.p.m. series no difference in latency time was observed between the sexes.

The first death due to tumour occurred at 36 weeks of exposure in the 50 p.p.m. series and at 32 weeks in the 500 p.p.m. series.

\section{DISCUSSION}

VC is a potent multipotential carcinogen causing multiple tumours in experimental test systems, such as rats (Viola et al. 1971, Maltoni 1975), mice (Maltoni, Keplinger et al. 1975) and hamsters (Maltoni) irrespective of administration route, and also a mutagenic substance, at least after metabolic activation (Huberman et al. 1975, Rannug et al. 1976).

The frequency of animals bearing any type of tumour was $100 \%$ in our 500 p.p.m. series and $71 \%$ in the 50 p.p.m. series. A tendency to a dose-response relationship may thus be seen. The dose-frequency relationship is more pronounced when the multiplicity of lung adenomas is concerned. Thus, 500 p.p.m. generally induces multiple lung tumours over the whole lung, while only a few animals exposed to 50 p.p.m. had more than one tumour in the lung. The exposure to the higher dose level resulted also in tumour foci of generally larger size than exposure to the low dose level.

On the other hand, when considering haemangiosarcomas, a tendency to an inverted dose-frequency relationship might be suggested by the fact that 14 out of 16 animals in the 50 p.p.m. group were found with this type of tumour but only eight out of 16 among the 500 p.p.m. animals. The mean number of tumours per animal (1.7) is the same for both dose groups cal- 
culated on the total number of animals used in each group. When the mean number of tumours is calculated on the number of tumour bearing animals only, the mean number of tumour per animal in the 50 p.p.m. group, on the other hand, increases to 2.3 . It is in this connection interesting that for other carcinogens, such as pentacyclic hydrocarbons (Cramer \& Stowell 1943, Payne et al. 1960, Wynder et al. 1960), it has also been observed that a low exposure during a longer time may intensify the biological response, comparing to a high exposure during a short time period, or comparing to single exposure.

In animals exposed to 500 p.p.m. the first malignant tumour (mammary carcinoma) was observed already at 26 weeks, although the first tumour death occurred at 32 weeks. If mammary carcinoma is accepted as a consequence of VC exposure, as suggested by other data (Maltoni), this might indicate that 500 p.p.m. for 26 weeks is sufficient to induce malignant tumours Thus, the "threshold time" - or minimal true induction time - for malignant tumours is shorter than 26 weeks for 500 p.p.m. It is to be noted that the exposure to 500 p.p.m. was terminated at 26 weeks. Exposure to 50 p.p.m. did, however, not induce other tumours than two lung adenomas during the first six months and no conclusion can be drawn about the true induction time for this dose level. The first death due to tumour among the 50 p.p.m. animals occurred after 36 weeks.

A tendency to a dose-dependent latency time may thus be suggested, when considering the time of the first death in malignant tumour. The higher dose level was thus associated with a decreased latency time at four weeks. The higher dose level was also associated with a decrease in 11 weeks, when mean survival time is considered. This is in accordance with the inverted relationship between dose and latency time, which is a well-known observation for other carcinogens (Bryan \& Shimkin 1943). The difference in mean survival time between sexes exposed to 50 p.p.m. might also indicate that female mice are more sensitive to low dose levels of $\mathrm{VC}$ than male mice.

The majority of tumours in mice exposed to 50 and 500 p.p.m. of VC was lung adenomas. This was also observed by Maltoni, who noted a tendency to malignant transformation of lung tumours 61 weeks after exposure to 50 p.p.m. VC 4 hrs./day, five days/week for 30 weeks (30,000 p.p.m. hrs.). In spite of a total dose rate of 78,000 p.p.m. hrs. for 50 p.p.m. in our experi- 
ment we could not find any sign on malignant transformation in the lung tissue.

The term alveologenic adenoma implies a histologically benign tumour. On the other hand, the occurrence of multiple benign tumours in the lungs considerably decreases the respiratory capacity and may lead to immediate death of the animal during a stress situation, for instance during narcosis. This rises the problem of evaluation of chemically induced benign tumours. Thus, it has been angued that the induction of some benign tumours, such as hepatomas, in mice (Grasso \& Crampton 1972) does not indicate chemical carcinogenicity. On the other hand, there seems to exist no situation where a chemical substance induces solely benign tumours (Tomatis et al. 1973). The same compound may induce malignant tumours at higher dose levels or after a prolonged administration period and/or observation time. Furthermore, a compound, like benzidin (Prokofjeva 1971) or B-naftylamine (Bonser et al. 1956), which induces histopathologically benign tumours in mice, may very well induce malignant tumours in other species, including man. From an evaluation point of view, as regards the carcinogenic risk to man, the difference between benign and malign tumours in the lungs of mice exposed to VC may thus not be very important, especially as malignant haemangiosarcomas occur in various other organs together with lung ademonas a few weeks later.

A common feature in Maltoni's and our experiment is that the proportion of tumours of vascular origin is higher at a low dose level. The angiosarcomas of the liver are, however, in absolute minority, a fact which is important in the evaluation of the carcinogenic risk to man after occupational exposure to VC.

Haemangiosarcomas of various organs seem to be a notable characteristic of VC-exposed mice, implicating that the blood vessels play an important role in the biological activity of VC. This is furthermore corroborated by the presently reported observation that blood vessel rupture may easily occur in haemangiosarcoma-bearing mice and by the presence of blood vessel dilation in the liver (telangiectasis), without any other pathological liver change. That the blood vessels may be involved in the pathogenesis of VC induced liver tumours has been suggested (Thomas \& Popper 1975), but blood vessel disturbances are even a more general feature of VC toxicity than mere carcinogenesis.

This is evident from the presence of Raynaud's phenomenon 
and the acroosteolysis of VC-exposed workmen (for further references, see Holmberg \& Molina 1974) and is furthermore suggested by an overrepresentation in deaths of circulatory diseases, as observed among Swedish VC/PVC-workers (Byrén et al. 1976).

All subperitoneal and subcutaneous haemangiosarcomas presently observed were located in fat tissue. Histologically the pararenal tumours, for instance, were distinctly separated from the kidney tissue. VC is, like other agents with anesthetic effects, lipophilic and the appearance of almost all haemangiosarcomas in fat tissue may reflect that physical characteristic. The VC concentration in fat might be comparatively very high, while the concentration of the shortlived possible ultimate carcinogen (Van Duuren 1975), the highly mutagenic (Rannug et al. 1976) chloroethylene epoxide is probably low. As white fat generally is a slowly metabolising tissue, one might speculate that the epoxidation is merely performed in the endothelial cells of the blood vessels at transport to and from fat tissue, thus subjecting these cells to genetic damage leading to neoplastic transformation.

The presence of haemangiosarcomas in fat tissue would suggest that VC-induced tumours might be found also in the central nervous system. This was not the case in this experiment, nor in previous experimental studies. A tendency to an increased frequency of brain tumours was, however, observed in an epidemiological study on around 8,300 workers in PVC-polymerization industries in USA (Tabershaw \& Gaffey 1974).

\section{ACKNOWLEDGEMENT}

The authors are indebted to Aina Ekner, Annika Eriksson, Ella Jensen, Ulla Hammarström and Gun Lindkvist for technical assistance and to Inge Ericsson for preparing photographs.

\section{REFERENCES}

Bartsch, H. \& R. Montesano: Mutagenic and carcinogenic effects of vinyl chloride. Mutation Res. 1975, 32, 93-114.

Bonser, G. M., D. B. Clayson, J. W. Jull \& L. N. Pyrah: The carcinogenic activity of 2-naphtylamine. Brit. J. Cancer 1956, 10, 533538.

Bryan, W. R. \& M. B. Shimkin: Quantitative analysis of dose-response data obtained with three carcinogenic hydrocarbons in strain C3H male mice. J. nat. Cancer Inst. 1943, 3, 503-531. 
Byrén, D., G. Engholm, A. Englund \& P. Westerholm: Mortality and cancer morbidity in a group of Swedish VCM/PVC production workers. Environ. Hlth Persp. In press 1976.

Cramer, W. \& R. E. Stowell: On the quantitative evaluation of experimental skin carcinogenesis by methylcholanthrene. The factors of dosage, time, spacing of applications and the multiplicity of the carcinogenic response. Cancer Res. 1943, 3, 668-681.

Ducatman, A., K. Hirschhorn \& I. J. Selikoff: Vinyl chloride exposure and human chromosome aberrations. Mutation Res. 1975, 31, $163-168$.

Van Duuren, B. L.: On the possible mechanism of carcinogenic action of vinyl chloride. Ann. N. Y. Acad. Sci. 1975, 246, 258-267.

Funes-Cravioto, F., B. Lambert, J. Lindsten, L. Ehrenberg, A. T. Natarajan \& S. Osterman-Golkar: Chromosome aberrations in workers exposed to vinyl chloride. Lancet 1975, 1 (No. 7904), 459.

Grasso, $P . \& R$. F. Crampton: The value of the mouse in carcinogenicity testing. Food Cosmet. Toxicol. 1972, 10, 418-426.

Holmberg, B. \& G. Molina: The industrial toxicology of vinyl chloride. A review. W.-Environm.-Hlth. 1974, 11, 138-144.

Huberman, E., H. Bartsch \& L. Sachs: Mutation induction in chinese hamster V79 cells by two vinyl chloride metabolites, chloroethylene oxide and 2-chloroacetaldehyde. Int. J. Cancer 1975, $16,639-644$.

Keplinger, M. L., J. W. Goode, D. E. Gordon \& J. C. Calandra: Interim results of exposure of rats, hamsters and mice to vinyl chloride. Ann. N. Y. Acad. Sci. 1975, 246, 219-224.

Lloyd, W. J.: Angiosarcoma of the liver in vinyl chloride/polyvinyl chloride workers. J. occup. Med. 1975, 17, 333-334.

Loprieno, N., R. Barale, S. Baroncelli, C. Bauer, G. Bronzetti, A. Cammellini, G. Cercignani, C. Corsi, G. Gervasi, C. Leporini, R. Nieri, A. M. Rossi, G. Stretti \& G. Tureni: Evaluation of the genetic effects induced by vinyl chloride monomer (VCM) under mammalian metabolic activation: studies in vitro and in vivo. Mutation Res. 1976, 40, 85-96.

Maltoni, C.: The value of predictive experimental bioassays in occupational and environmental carcinogenesis. Ambio 1975, 4, 1823.

Payne, W. W. \& W. C. Hueper: The carcinogenic effects of single and repeated doses of 3,4-benzpyrene. Amer. industr. Hyg. Ass. J. $1960,21,350-355$.

Prokofjeva, $O$. G.: Induction of hepatic tumours in mice by benzidine. Vop. Onkol. 1971, 17, 61-64.

Rannug, U., A. Johansson, C. Ramel \& C. A. Wachtmeister: The mutagenicity of vinyl chloride after metabolic activation. Ambio $1975,3,194-197$. 
Rannug, U., R. Göthe \& C. A. Wachtmeister: The mutagenicity of chloroethylene oxide, chloroacetaldehyde, 2-chloroethanol and chloroacetic acid, conceivable metabolites of vinyl chloride. Chem.-biol. Interactions 1976, 12, 251-263.

Tabershaw, I. R. \& W. R. Gaffey: Mortally studies of workers in the manufacture of vinyl chloride and its polymers. J. occup. Med. $1974,16,509-518$.

Thomas, L. B. \& H. Popper: Pathology of angiosarcoma of the liver among vinyl chloride polyvinyl chloride workers. Ann. N. Y. Acad. Sci. 1975, 246, 268-277.

Tomatis, L., C. Partensky \& R. Montesano: The predictive value of mouse liver tumour induction in carcinogenicity testing - a literature survey. Int. J. Cancer 1973, 12, 1-20.

Viola, P. L., A. Bigotti \& A. Caputo: Oncogenic response of rat skin, lungs and bones to vinyl chloride. Cancer Res. 1971, 31, 516522.

Winell, M., B. Holmberg \& T. Kronevi: Biological effects of vinyl chloride - an experimental study. Environ. Hlth Persp. In press 1976.

Wynder, E. L., J. W. Spranger \& M. M. Fark: Dose-response studies with benzo (a) pyrene. Cancer (Philad.) 1960, 13, 106-110.

\section{SAMMANFATTNING}

Patologisk-anatomiska förändringar hos möss exponerade för vinylklorid.

NMRI-albino-möss inhalerade 50 och 500 ppm vinylklorid 6 tim/ dag, 5 dagar/vecka under 52 respektive 26 veckor. Histologiskt benigna alveolära lungadenom, hemangiosarkom i fettvävnaden och ett fåtal andra benigna och maligna tumörer påträffades i olika lokalisationer. Endast ett djur hade leverhemangiosarkom. Samtliga djur exponerade för $500 \mathrm{ppm}$ uppvisade tumörer; i 50 ppm-gruppen hade $71 \%$ av djuren tumörer. Tumörfrekvens, antalet tumörfoci och focusdiametrar i båda grupperna antyder en dos-respons-relation. Hemocoeli, beroende på ruptur av hemangiosarkom, var en vanlig dödsorsak. Telangiectasi i levern observerades hos några djur. Fettvävnadens och blodkärlens roll i vinylkloridens patologi diskuteras.

(Received July 15, 1976).

Reprints may be requested from: B. Holmberg, assoc. professor, National Board of Occupational Safety and Health, P. O. Box S-100 26, Stockholm, Sweden. 